\title{
PENGEMBANGAN KAIN RAJUT DENGAN EFEK ILUSI OPTIK UNTUK KAIN SANDANG MENGGUNAKAN MESIN RAJUT SINGLE KNIT SEMI SEAMLESS
}

\author{
KNIT FABRICS WITH OPTICAL ILLUSION EFFECTS FOR CLOTHING \\ FABRIC USING SINGLE KNIT SEMI SEAMLESS MACHINE
}

\author{
Dermawati Suantara, Yusniar Siregar, Rizal Fahruroji
}

\author{
Balai Besar Tekstil, Jalan Jenderal Ahmad Yani No. 390 Bandung \\ E-mail: texirdti@bdg.centrin.net.id
}

Tanggal diterima: 28 Nopember 2018, direvisi: 29 Desember 2019, disetujui terbit: 29 Desember 2019

\begin{abstract}
ABSTRAK
Proses pembuatan kain rajut dalam penelitian ini menggunakan mesin Single Knit Santoni Jacquard MF 8, gauge 14 GG, diameter 14 inci, 8 feeder, jumlah jarum 1248 jarum, dan kecepatan 44 rpm, dimana jeratan knit dan welt dapat menghasilkan motif jacquard yang bervariasi, salah satu motif dengan ilusi optik. Bahan baku yang digunakan adalah benang poliester, kapas, nylon dan lycra. Pada penelitian ini kain rajut dibuat menjadi 3 variasi desain ilusi optik yang sama. Pemakaian benang nilon dan lurex dalam penelitian ini bertujuan untuk memperoleh kain rajut dengan efek yang berbeda yaitu adanya efek kilau dari benang lurex yang berwarna perak. Kain rajut yang terdiri dari jeratan -jeratan benang mengalami perubahan bentuk, karena sifatnya yang fleksibel. Dari hasil pengujian ketahanan jebol, kain rajut kapas, poliester, dan nilon memiliki interval waktu jebol yang hampir sama namun distension (jarak) sampai terjadinya jebol pada kain rajut nilon adalah yang tertinggi yaitu $17.7 \mathrm{~mm}$. Sedangkan pada kain rajut kapas dan poliester masing-masing adalah $14.4 \mathrm{~mm}$ dan $14.9 \mathrm{~mm}$. Kain rajut nilon memiliki ketahanan jebol tertinggi yaitu $960.9 \mathrm{kPa}$ dibandingkan dengan kain kapas (725.9 kPa) dan kain poliester $(752.5 \mathrm{kPa}) . \mathrm{Hal}$ ini berbanding lurus dengan sifat kekuatan tarik seratnya dimana sifat kekuatan tarik serat nilon lebih tinggi dibandingkan serat poliester dan kapas. Mengacu pada standar SNI 2367:2008, ketiga jenis kain rajut yang diuji masih memenuhi persyaratan mutu ketahanan jebol yaitu minimum $686.4 \mathrm{kPa}$. Hasil uji ketahanan luntur warna kain terhadap pencucian rumah tangga, gosokan dan keringat menunjukkan hasil yang sesuai dengan persyaratan mutu SNI 2367:2008, yaitu 4-5. Ilusi optik pada kain lebih terlihat ketika konstruksi kain dibuat semakin rapat.
\end{abstract}

Kata kunci: kain rajut, ilusi optik, single knit

\section{ABSTRACT}

The process of making knit fabrics in this research is using Single Knit Santoni Jacquard MF 8 engine, gauge 14 GG, 14 inch diameter, 8 feeder, the number of needles 1248 needles, and the speed of 44 rpm, where knit and welt trap can produce a variety of jacquard motifs, one of motif with optical illusion. The raw materials using polyester yarn, cotton, nylon and lycra. In this research knitted fabric made in 3 variations with the same optical illusion design. The use of nylon and lurex yarn in this study aims to obtain knit fabrics with different effects that is the effect of luster from the silver colored lurex. Knitted fabrics consisting of twisted-yarn strands are deformed, due to their flexible nature. From the results of the breakthrough test, cotton knit, polyester, and nylon fabrics have nearly equal time intervals but the distension (distance) until the occurrence of bursts on nylon knit fabric is the highest of $17.7 \mathrm{~mm}$. In cotton and polyester knit fabrics are respectively $14.4 \mathrm{~mm}$ and $14.9 \mathrm{~mm}$. Nylon fabrics have the highest breakthrough resistance of $960.9 \mathrm{kPa}$ compared to cotton fabrics $(725.9 \mathrm{kPa})$ and polyester fabrics $(752.5 \mathrm{kPa})$. This is directly proportional to the nature of its fiber tensile strength. While the tensile strength properties of nylon fibers are higher than polyester and cotton fibers. Refers to SNI 2367: 2008 standard, the three types of knitting fabric that is tested still fulfill the quality requirements of resistance broken which is a minimum of $686.4 \mathrm{kPa}$. The results of the cloth color fastness test against household wash, rubbing and sweat showed results that match with the expected quality requirements SNI 2367:2008, that is 4-5. Optical illusion in the overall look of fabric seen when the construction of the fabric made more tightly.

Keywords: knitting fabric, optical illusion, single knit 


\section{PENDAHULUAN}

Kain rajut telah diketahui dapat memberikan kualitas kenyamanan yang baik dan telah sejak lama digunakan pada berbagai jenis pakaian. ${ }^{1}$ Struktur rajut terbentuk dari baris-baris jeratan yang bersambung secara kontinyu. Karakteristik kain rajut pada dasarnya ditentukan oleh kebergantungan suatu jeratan terhadap jeratan-jeratan di sekitarnya seperti jeratan pada sisinya, jeratan diatas maupun dibawahnya. ${ }^{2,}{ }^{3}$ Struktur kain rajut tentunya akan mempengaruhi sifat fisika dan kimia kain rajut dan berkaitan dengan kenyamanan pakai kain tersebut. Struktur rajut merupakan elemen penting untuk menghasilkan tampilan yang baik pada desain pakaian rajut.

Pada penelitian ini proses pembuatan kain rajut menggunakan mesin Santoni Single Knit Semi Seamless. Mesin ini dapat membuat jeratan knit dan welt. Jeratan knit dan welt merupakan jeratan dasar pada rajut pakan, seperti terlihat pada gambar berikut : ${ }^{4}$

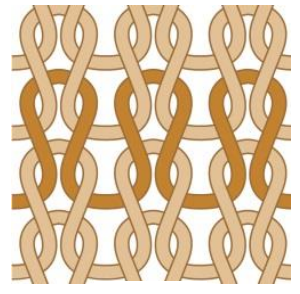

(a)

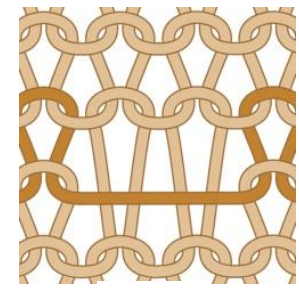

(b)

\section{Gambar 1. (a) Jeratan Knit, (b) Jeratan Welt}

Jeratan welt tidak dapat terlihat pada permukaan depan kain rajut dan tidak dapat terbentuk tanpa ada jeratan knit. Sifat unik dari jeratan welt tersebut menyebabkan pengurangan lebar, panjang, dan elastisitas dari kain rajut. ${ }^{5}$ Pada mesin rajut seamless jacquard yang digunakan dalam penelitian ini, jeratan knit dan welt dapat menghasilkan motif jacquard yang bervariasi. ${ }^{6}$

Pada penelitian ini mesin rajut bundar menggunakan jacquard sistem elektronik. Mesin rajut bundar dengan peralatan jacquard dilengkapi dengan mekanisme penggerak silinder jarum yang secara opsional dapat mengendalikan gerakan putaran silinder jarum sesuai dengan pola yang akan dirajut. Sebuah motor yang saling bertautan melalui roda gigi dengan silinder jarum berputar sesuai prosedur rotasi silinder jarum yang disimpan sebelumnya di media memori magnetik. Aktuator jarum beroperasi sesuai dengan prosedur pembentuk pola yang tersimpan dalam media memori magnetik lain karena sinyal disediakan oleh sensor untuk mendeteksi gerakan rotasi silinder jarum. Dengan demikian kain rajut jacquard yang memiliki pola yang telah ditentukan dapat dirajut secara efisien. ${ }^{7}$
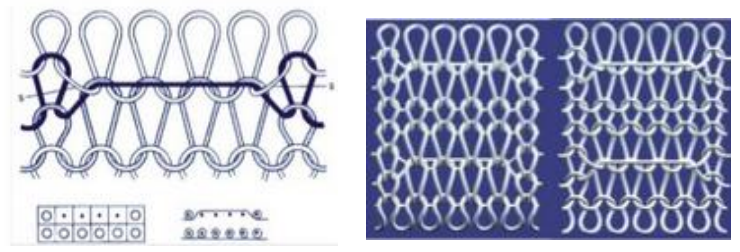

Gambar 2. Gabungan jeratan knit dan welt

Teknologi rajut semi seamless dapat menghasilkan produk garmen tanpa proses pemotongan (cutting) dan sedikit tambahan proses penjahitan akhir. Teknologi semi seamless adalah suatu konsep inovasi pakaian tanpa jahitan pada sisinya. Teknologi semi seamless ini memiliki kelebihan yaitu dapat memberikan keleluasaan gerakan dan kenyamanan bagi pemakai, lebih ringan karena tidak ada jahitan pinggir kain seperti pada kain rajut konvensional. Selain itu mesin rajut semi seamless ini sangat cocok untuk pembuatan pakaian yang tepat sesuai ukuran tubuh. Motif dan pola pada produk kain rajut semi seamless dapat terlihat karena adanya perbedaan jeratan dan jenis benang pada bagian tertentu, seperti terlihat pada Gambar 3.
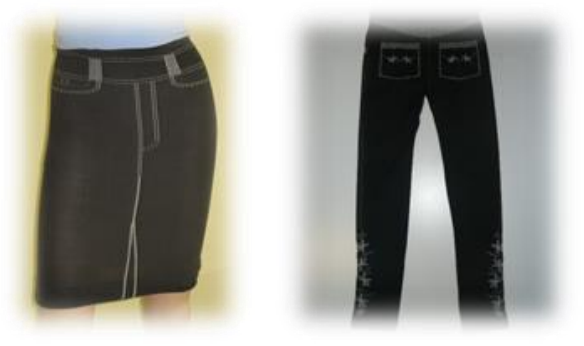

Gambar 3. Contoh produk mesin rajut MF8

Proses pembuatan desain dan pemolaan dapat dilakukan dengan menggunakan program software (penelitian ini menggunakan software Graph 6). Hal ini memberikan peluang untuk mendesain dan menghasilkan garmen untuk pakaian pria/wanita dengan ukuran dan bentuk yang bervariasi. $^{8}$

Ilusi gerak, salah satu ilusi optik yang paling menghibur, yang berdasar pada ilusi yang muncul dari image atau gambar statis yang nampak bergerak, berdasarkan pada penggunaan warnawarna kontras yang berinteraksi satu sama lain.
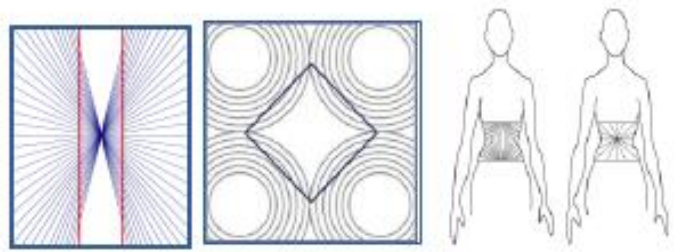

Gambar 4. Ilusi Hering 
Ilusi optik paling baik dihasilkan oleh berbagai jenis garis yang berbeda. Secara psikologis, garis membuat mata berputar dan mengontrol otak kita sedemikian rupa sehingga mata kita mengikuti dan mengarah pada desain motif tersebut. Ketika garis-garis menyatu (bertemu), mata mengikutinya ke titik fokus yang membuat bagian tubuh manusia terlihat lebih kecil. Sebaliknya, saat garis bergerak menjauh (menyimpang) satu sama lain, mata kita mengikuti garis-garis tersebut sampai ujung, yang menjadi titik fokus, dan membuat tubuh manusia terlihat lebih lebar. ${ }^{9}$

Ilusi gerak merupakan sensasi mempertimbangkan sebagai tahap pertama persepsi. Bagaimanapun, persepsi mempertimbangkan proses kompleks yang terjadi melalui penerimaan, interpretasi, pemilihan dan pengaturan sensor informasi. Persepsi adalah suatu konsep dimana subjek dari bagian seperti psikologi, fisiologi dan seni. ${ }^{10}$ Mata manusia mempunyai kemampuan untuk melihat dibawah kondisi dengan sumber cahaya yang kuat atau lemah, dan beradaptasi sendiri terhadap situasi tersebut.

Proses persepsi secara visual dimulai sebagai individu yang memulai untuk mengimplementasikan proses penglihatan melalui pemilihan gambar (image) dari warna yang jangkauannya luas, bentuk, dan objek-objek di lingkungan sekitar. Membandingkan garis horizontal yang sama panjang dengan garis vertikal, sebenarnya meninggalkan kesan seperti lebih panjang dibandingkan dengan garis horisontal. ${ }^{11}$

Selama satu dekade terakhir, perkembangan mode menjadi lebih ekspresif dan berani serta terispirasi oleh perkembangan mode dunia yang bergerak cepat dan dinamis, Konsumen cenderung lebih responsif terhadap gaya (trend) terbaru dibanding dengan tahun-tahun sebelumnya, sehingga tak hanya modis, kenyamanan, kemudahan perawatan serta daya tahan merupakan komponen penting dari produk sangat diperhatikan.

Pakaian rajut merupakan komponen penting dari industri fashion dan pakaian. Teknologi maju, seperti fully-fashioned dan rajut seamless, menawarkan keuntungan baru untuk desain rajut garmen untuk memperbaiki kesesuaian dan meningkatkan estetis (keindahan). Rajut ilusi atau rajut bayangan adalah suatu bentuk dari seni tekstil, dimana rajutannya dilihat hanya berupa garis-garis sempit dari satu sudut, dan sebagai satu gambar ketika dilihat dari sudut yang lain. Rajut ilusi telah diakui sebagai suatu bentuk seni sejak tahun $2010 .^{12}$

Meski tidak terlalu perlu mengacu pada perkembangan trend mode dunia, Indonesia begitu kaya akan kreativitas, inovasi produk dari mesin rajut seamless dapat dikembangkan yang disesuaikan dengan kedinamisan pasar/ konsumen. ${ }^{13}$ Inovasi produk menjadi sangat penting dan dibutuhkan, namun IKM/UMKM rajut terkadang mengalami kesulitan didalam menyesuaikan dengan perkembangan selera pasar yang terus menerus mengalami perubahan.

Mode menjadi ranah yang menjelma sebagai surga kebebasan berimajinasi, berkreasi, dan bergaya. Hal itulah yang turut diujarkan perancang ternama dunia, Coco Chanel, "Fashion is not something that exists in dresses only. Fashion is in the sky, in the street, fashion has to do with ideas, the way we live, what is happening". ${ }^{14}$

Dalam melakukan kegiatan penelitian tentang rajut seamless, penelitian menempatkan perajutan sebagai proses aditif kain tekstil, yang aplikasinya mempunyai potensi dalam konteks desain yang lebih luas dari tekstil, industri pakaian dan alas kaki (footwear). ${ }^{15}$ Balai Besar Tekstil (BBT) sebagai lembaga penelitian dan pengembangan bidang tekstil selalu berupaya meningkatkan kemampuan dalam kegiatan litbangnya. Salah satu upaya yang dilakukan adalah dengan meningkatkan kinerja mesin rajut single knit semi seamless yang terdapat di Gedung PDDC (Product Development and Design Center) BBT dalam mengembangkan produk rajut, khususnya produk rajut dengan motif ilusi optik. ${ }^{16}$

\section{METODE}

Diagram alir penelitian dilakukan sebagaimana ditunjukkan pada Gambar 5.

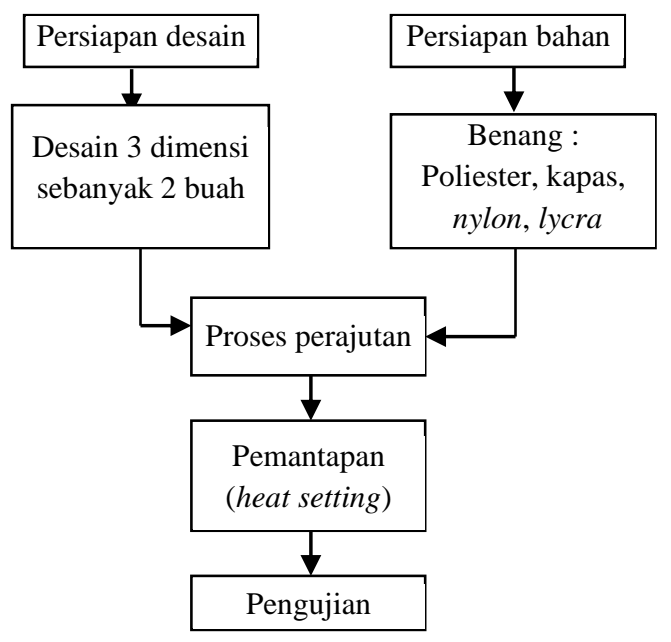

Gambar 5. Diagram alir penelitian

\section{Bahan dan Peralatan}

Bahan baku dalam penelitian ini adalah benang poliester, kapas, nylon dan lycra. Peralatan yang digunakan adalah mesin rajut single knit semi seamless.

\section{Proses Persiapan Desain}

Pada penelitian ini dibuat 3 variasi kain rajut dengan desain ilusi optik yang sama yaitu benang kapas, poliester, dan nilon. Tahap awal dalam 
perencanaan dan pembuatan desain adalah pembuatan desain motif ilusi sebanyak 2 motif yang akan diaplikasikan pada kain rajut semi seamless. Dalam pembuatannya, motif digambar melalui komputer menggunakan software Corel Draw, kemudian disave kedalam bentuk jpeg untuk ditracing ulang kedalam bentuk psd (Photoshop).

Jeratan yang dipakai didalam membuat kain rajut dengan ilusi optik yaitu jeratan dasar seperti yang terlihat pada Gambar 7.

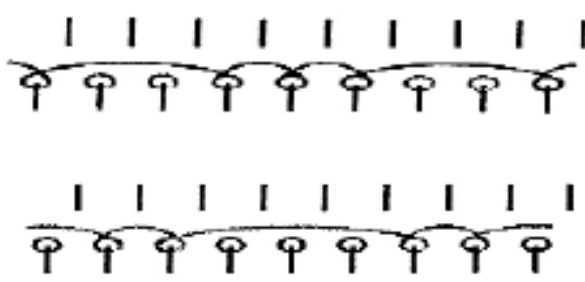

Gambar 7. Jeratan dasar desain jacquard

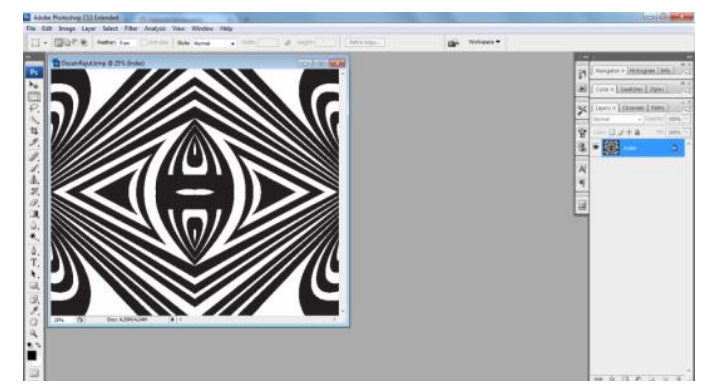

Gambar 6. Motif kain dalam bentuk .psd (photoshop)

\section{Mesin}

Mesin yang digunakan dalam penelitian ini adalah Mesin Rajut Bundar Seamless Single Knit, jacquard system, rpm. 50 - 150, sistem on-line dan integrated, merek Santoni, tipe MF8, kehalusan jarum (Gauge) 28 jarum per inci, operasi desain dengan komputer, dan diameter mesin 14 inci. Mesin rajut jacquard yang digunakan dalam penelitian ditunjukkan pada Gambar 8.

\section{Proses Perajutan}

Pada persiapan proses perajutan, motif yang telah dibuat dalam bentuk psd, seperti pada Gambar 6 akan ditransfer ke software Graph 6 untuk dilanjutkan ke mesin rajut.

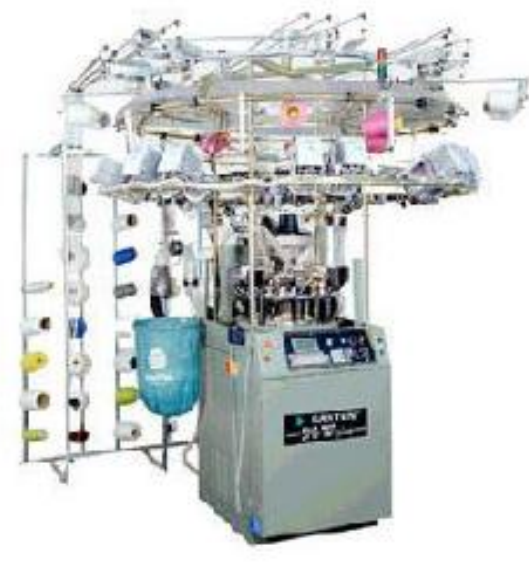

Gambar 8. Mesin rajut bundar seamless single knit

Proses perajutan dilakukan dengan menggunakan Mesin Rajut Bundar Single Knit Santoni Jacquard MF 8, gauge 14 GG, diameter 14 inci, 8 feeder, jumlah jarum 1248 jarum, dan kecepatan $44 \mathrm{rpm}$. Desain ilusi optik menggunakan jeratan knit dan welt (miss), karena disini hanya ada silinder saja. Hasil kain rajut diuji dan dibandingkan dengan spesifikasi kain rajut untuk blus dan kemeja (SNI 2367:2008).

\section{Pengujian}

Pengujian yang dilakukan pada kain rajut dengan ilusi optik ini mengacu pada SNI 2367:2008: Kain rajut pakan untuk blus dan kemeja, antara lain:

1. Konstruksi kain rajut

2. Kekuatan jebol (SNI 08-0617:1989: Cara Uji Kekuatan Jebol Kain Rajut)

3. Perubahan dimensi kain (SNI ISO 5077:2011: Cara Uji Perubahan Dimensi pada Pencucian dan Pengeringan)

4. Tahan luntur warna terhadap:

- Pencucian

- Gosokan (SNI 12947-1:2010: Cara Uji Tahan Gosok Kain)

- Keringat

\section{HASIL DAN PEMBAHASAN}

Gambar 9 menunjukkan hasil penelitian pembuatan kain rajut dengan ilusi optik. Hasil gambar dalam bentuk psd (photosop) menunjukkan desain geometri yang tampak jelas dan tajam menimbulkan ilusi gambar yang seakan bergerak (motif 1). Pada kain rajut, gambar yang dihasilkan sama namun efek ilusi optiknya tidak setajam pada gambar awal. 

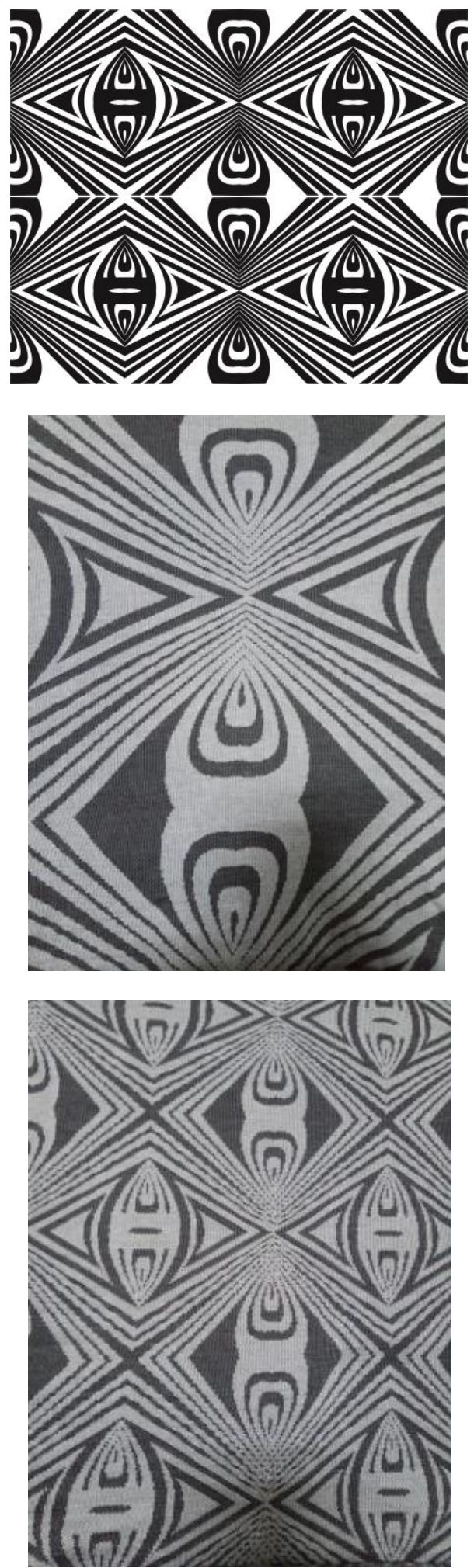

Gambar 9. Motif ilusi optik pada kain rajut: a) Motif 1; b) Desain 1; c) Desain 2.

Pada desain 1 motif ilusi optik dibuat dengan skala yang lebih besar dibandingkan dengan desain 2. Perbedaan ukuran gambar inipun menghasilkan efek ilusi optik yang berbeda, dimana motif yang lebih kecil menghasilkan efek ilusi optik yang lebih jelas dibandingkan dengan motif sama dengan ukuran lebih besar. Hal ini disebabkan oleh struktur kain rajut yang membentuk desain ilusi optik tersebut terdiri dari lengkungan-lengkungan jeratan, sehingga pada pinggiran motif di kain tampak bergelombang. Selanjutnya dalam penelitian ini dilakukan percobaan menggunakan 3 jenis variasi benang dengan hasil sebagai berikut.

Tabel 1 menunjukkan bahwa kain yang menggunakan benang nilon memiliki konstruksi kain paling rapat ke arah course dibandingkan dengan kain kapas dan nilon karena diameter benang yang lebih kecil dibandingkan dengan benang kapas dan poliester. Hal ini berpengaruh terhadap tampilan desain kain secara keseluruhan, konstruksi kain semakin rapat, akan semakin terlihat ilusi optik yang dihasilkan pada kain rajut. Pemakaian benang nilon dan lurex dalam penelitian ini bertujuan untuk memperoleh kain rajut dengan efek yang berbeda yaitu adanya efek kilau dari benang lurex yang berwarna perak.

Tabel 1. Konstruksi kain rajut

\begin{tabular}{clcc}
\hline Kain & Jenis benang & \multicolumn{2}{c}{ Konstruksi kain rajut } \\
\cline { 3 - 4 } & & Wale/inci & Course/inci \\
\hline A & Kapas Ne 30 & 34 & 57 \\
\hline B & $\begin{array}{l}\text { Poliester } \\
\text { Stapel Ne 30 }\end{array}$ & 32 & 65 \\
\hline C & $\begin{array}{l}\text { Nilon Ne 70 } \\
\text { dan benang } \\
\text { Lurex }\end{array}$ & 35 & 94 \\
\hline
\end{tabular}

Kain rajut yang terdiri dari jeratan-jeratan benang sangat memungkinkan untuk terjadinya perubahan bentuk, karena sifatnya yang fleksibel. Dari hasil pengujian ketahanan jebol, dapat dilihat bahwa kain rajut kapas, poliester, dan nilon memiliki interval waktu jebol yang hampir sama namun distension (jarak) sampai terjadinya jebol pada kain rajut nilon adalah yang tertinggi yaitu $17.7 \mathrm{~mm}$. Pada kain rajut kapas dan poliester masing-masing adalah $14.4 \mathrm{~mm}$ dan $14.9 \mathrm{~mm}$, hal tersebut dikarenakan bahan baku nilon mempunyai daya tahan sangat kuat dan kekuatan tarik yang tinggi dibandingkan kapas dan polyester.

Pada Gambar 10, dapat dilihat bahwa kain rajut nilon memiliki ketahanan jebol tertinggi yaitu $960.9 \mathrm{kPa}$ dibandingkan dengan kain kapas (725.9 $\mathrm{kPa})$ dan kain poliester $(752.5 \mathrm{kPa})$. Hal ini berbanding lurus dengan sifat kekuatan tarik seratnya. Seperti terlihat pada Tabel 1 serat nilon memilikit sifat kekuatan tarik yang lebih tinggi dibandingkan serat poliester dan kapas. Namun ketiga jenis kain tersebut masih memenuhi persyaratan mutu ketahanan jebol menurut SNI 2367 : 2008, yaitu minimum $686.4 \mathrm{kPa}$. 


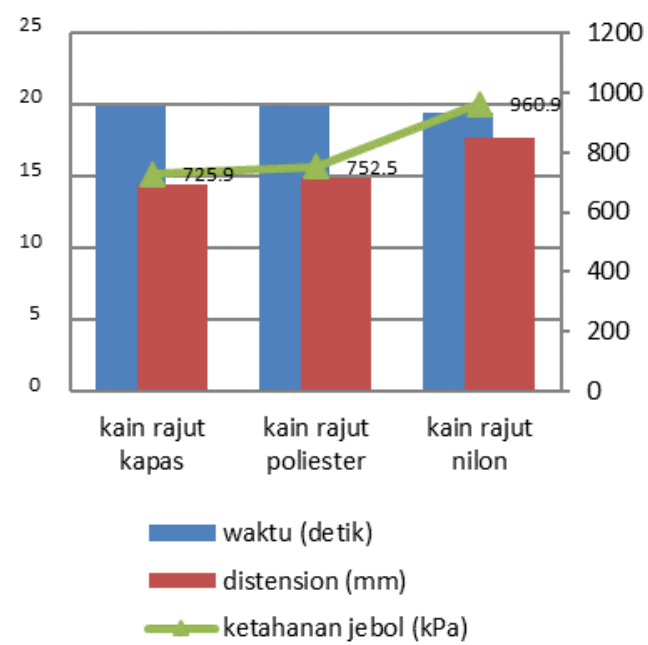

Gambar 10. Hasil uji ketahanan jebol kain
Hasil uji tahan luntur warna kain rajut dapat dilihat pada Tabel 2. Hasil uji ketahanan luntur warna kain terhadap pencucian rumah tangga, gosokan dan keringat menunjukkan hasil yang sesuai dengan persyaratan mutu yang diharapkan, yaitu 4-5. Pada ketiga variasi kain rajut yaitu kain rajut kapas, poliester, dan nilon tidak terlihat perbedaan hasil uji ketahanan luntur warna pada kain. Selain itu penggunaan motif ilusi optik pada kain rajut ini tetap menghasilkan sifat tahan luntur yang masih baik.

Tabel 2. Hasil uji ketahanan luntur warna

\begin{tabular}{|c|c|c|c|c|c|c|}
\hline \multirow{2}{*}{$\begin{array}{l}\text { No } \\
1\end{array}$} & \multicolumn{2}{|c|}{ Ketahanan luntur warna terhadap } & \multirow{2}{*}{$\begin{array}{r}\text { Kain A } \\
4-5\end{array}$} & \multirow{2}{*}{$\begin{array}{r}\text { Kain B } \\
4-5\end{array}$} & \multirow{2}{*}{$\begin{array}{r}\text { Kain C } \\
4-5\end{array}$} & \multirow{2}{*}{$\begin{array}{c}\text { SNI } \\
2367: 2008 \\
\text { Minimum } 4\end{array}$} \\
\hline & Pencucian & Perubahan warna & & & & \\
\hline & & Penodaan pada asetat & 4-5 & $4-5$ & $4-5$ & Minimum 4 \\
\hline & & Penodaan pada kapas & $4-5$ & $4-5$ & $4-5$ & \\
\hline & & Penodaan pada poliamida & $4-5$ & $4-5$ & $4-5$ & \\
\hline & & Penodaan pada poliester & $4-5$ & $4-5$ & $4-5$ & \\
\hline & & Penodaan pada akrilat & $4-5$ & $4-5$ & $4-5$ & \\
\hline & & Penodaan pada wol & $4-5$ & $4-5$ & $4-5$ & \\
\hline \multirow[t]{2}{*}{2.} & Gosokan & Kering & $4-5$ & $4-5$ & $4-5$ & Minimum 3-4 \\
\hline & & Basah & $4-5$ & $4-5$ & $4-5$ & Minimum 4 \\
\hline \multirow[t]{16}{*}{3.} & Keringat & Asam & & & & \\
\hline & & Perubahan warna & $4-5$ & $4-5$ & $4-5$ & Minimum 4 \\
\hline & & Penodaan pada asetat & $4-5$ & $4-5$ & $4-5$ & Minimum 4 \\
\hline & & Penodaan pada kapas & $4-5$ & $4-5$ & $4-5$ & \\
\hline & & Penodaan pada poliamida & $4-5$ & $4-5$ & $4-5$ & \\
\hline & & Penodaan pada poliester & $4-5$ & $4-5$ & $4-5$ & \\
\hline & & Penodaan pada akrilat & $4-5$ & $4-5$ & $4-5$ & \\
\hline & & Penodaan pada wol & $4-5$ & $4-5$ & $4-5$ & \\
\hline & & Basa & & & & \\
\hline & & Perubahan warna & $4-5$ & $4-5$ & $4-5$ & Minimum 4 \\
\hline & & Penodaan pada asetat & $4-5$ & $4-5$ & $4-5$ & Minimum 4 \\
\hline & & Penodaan pada kapas & $4-5$ & $4-5$ & $4-5$ & \\
\hline & & Penodaan pada poliamida & $4-5$ & $4-5$ & $4-5$ & \\
\hline & & Penodaan pada poliester & $4-5$ & $4-5$ & $4-5$ & \\
\hline & & Penodaan pada akrilat & $4-5$ & $4-5$ & $4-5$ & \\
\hline & & Penodaan pada wol & $4-5$ & $4-5$ & $4-5$ & \\
\hline
\end{tabular}

\section{KESIMPULAN}

Pembuatan kain rajut single knit dengan desain ilusi optik terdiri dari tiga variasi yaitu benang kapas, poliester, dan nilon. Kain yang menggunakan benang nilon memiliki konstruksi kain paling rapat ke arah course berpengaruh terhadap tampilan desain kain secara keseluruhan, konstruksi kain semakin rapat, maka semakin terlihat ilusi optik yang dihasilkan pada kain rajut. Hasil uji ketahanan jebol kain rajut nilon memberikan hasil ketahanan jebol tertinggi yaitu $960.9 \mathrm{kPa}$ dibandingkan dengan kain kapas dan poliester, namun ketahanan jebol pada ketiga jenis kain tersebut memberikan hasil yang sesuai standar SNI 2367 :2008. Hasil uji ketahanan luntur juga memberikan hasil yang sesuai standar. 
IKM/UMKM rajut dapat mengembangkan inovasi produk rajut dengan motif ilusi optik dan memanfaatkan mesin Rajut Bundar Seamless Single Knit, jacquard system, rpm. 50 - 150, sistem online dan integrated, merk Santoni, sehingga dapat menyesuaikan dengan perkembangan selera pasar yang terus menerus mengalami perubahan. IKM/ UMKM rajut juga dapat menawarkan keuntungan baru untuk desain rajut garmen untuk memperbaiki kesesuaian dan meningkatkan estetis (keindahan) dalam menghasilkan produk yang sesuai dengan kedinamisan pasar/ konsumen.

\section{PUSTAKA}

1. Nergiz, E., Yasemin, K. Effects of Knit Structure on the Dimensional and Physical Properties of Winter Outerwear Knitted Fabrics. Fibres and Textiles in Eastern Europe 16, (2008).

2. Abd El-Hady, R. A. M. Enhancing the Functional Properties of Weft Knitted Fabrics Made From Polyester Microfibers For Apparel Use. International Design Journal 4, (2018).

3. Ahmed, A., Moshiur, R., Farial, I. F. Effect of Knitted Structure on the Properties of Knitted Fabric. International Journal of Science and Research 4, (2015).

4. Sarah, V. Know Your Knits. Available at: http://www.threadsmagazine.com/item/4160/kn ow-your-knits/page/all (Accessed: 15 ${ }^{\text {th }}$ August 2017).

5. Kadolph, Sara. J. Textiles. Pearson 10, (2007).

6. Kotha, V. Basic of Knitting. Knitting News, (2010)
7. Ray, S. C. Fundamentals and Advances In Knitting Technology. Woodhead Publishing, (2011).

8. Saliha, A., Menekse, S. Design of Seamless Knitted Radiation Shielding Garments with 3D Body Scanning Technology. Procedia Technology 20, 123-132 (2015).

9. Verma, V., Kapila, P, B. Sc. Lines Aligned to Look Fine. Available at: http://textilelearner.blogspot.co.id/2016/06/line s-as-optical-illusion-on-dress.html. (Accessed: 08th August 2017).

10. Saliha, A., Menekse, S. Optical Illusions and Effects on Clothing Design. International Journal of Science Culture and Sport 3, (2015).

11. Gombrich, E.H. Sanat ve Yanisalma. The Story of Art. Phaidon 298, London, (1992).

12. Mariana, A. Indonesia dalam Pengembangan Inovasi Produk dan Kreativitas Berpengaruh Terhadap Diferensiasi Produk Melalui Kerajinan Tangan yang Mendulang Kesuksesan. Universitas Widyatama, Bandung, (2016).

13. Meredith, J. R., et al. Fashion Marketing and Management. Journal of Operations Management 8, New York, (2000)

14. Underwood, J. The Design of 3D Shape Knitted Preforms. School of Fashion and Textiles Design and Social Context Portfolio. RMIT University, (2009).

15. Moeliono, M. Pengembangan Produk Kain Rajut Menggunakan Mesin Rajut Bundar Seamless. Arena Tekstil 27(1), 45-54 (2012). 
Arena Tekstil Vol. 34 No. 2, 2019: 57-64 